\title{
The combination of sorafenib and radiation preferentially inhibits breast cancer stem cells by suppressing HIF-1 $\alpha$ expression
}

\author{
JAE HO LEE ${ }^{1,2}$, JAE WOONG SHIM ${ }^{1}$, YOO JIN CHOI ${ }^{1}, \mathrm{KYU} \mathrm{HEO}^{1}$ and $\mathrm{KWANGMO} \mathrm{YANG}^{1,3,4}$ \\ ${ }^{1}$ Research Center, Dongnam Institute of Radiological and Medical Sciences, Busan; ${ }^{2}$ Biospectrum Life Science Institute, \\ Seongnam-si, Gyeonggi-do; ${ }^{3}$ Department of Radiation Oncology, Dongnam Institute of Radiological and Medical Sciences, \\ Busan; ${ }^{4}$ Department of Radiation Oncology, Korea Institute of Radiological and Medical Sciences, Seoul, Republic of Korea
}

Received November 19, 2012; Accepted December 10, 2012

DOI: $10.3892 /$ or.2013.2228

\begin{abstract}
The importance of anticancer stem cell research for breast cancer lies in the possibility of providing new approaches for an improved understanding of anticancer activity and cancer treatment. In this study, we demonstrated that the preclinical therapeutic efficacy of combining the multikinase inhibitor sorafenib with radiation was more effective in hypoxia-exposed breast cancer stem cells. We assessed cell viability and Annexin V to evaluate the combined effect of sorafenib and radiation following exposure to hypoxia. Our results showed that the synergistic cytotoxicity increased tumor cell apoptosis significantly and reduced cell proliferation in MDA-MB-231 and MCF-7 cells under hypoxic conditions compared to sorafenib or radiation alone in vitro. Additionally, the combined treatment induced G2/M cell cycle arrest. Notably, the combination of sorafenib and radiation eliminated $\mathrm{CD} 44^{+} \mathrm{CD} 24^{-/ \text {low }}$ cells preferentially, which highly expressed hypoxia-inducible factor (HIF)-1 $\alpha$ and effectively inhibited primary and secondary mammosphere formation in MDA-MB-231 cells. A combined effect on MDA-MB-231 cells in response to hypoxia was shown by inhibiting angiogenesis and metastasis by suppression of HIF-1 $\alpha$ and matrix metalloproteinase-2 (MMP-2). Collectively, these results indicate that the efficacy of sorafenib combined with radiation for treating human breast cancer cells is synergistic and suggest a new therapeutic approach to prevent breast cancer progression by eliminating breast cancer stem cells.
\end{abstract}

\section{Introduction}

Breast cancer is the second most common cancer among Korean women. Numerous studies have been conducted on

Correspondence to: Dr Kwangmo Yang or Dr Kyu Heo, Research Center, Dongnam Institute of Radiological and Medical Sciences, 40 Jwadong-gil, Jangan-eup, Gijang-gun, Busan 619-953, Republic of Korea

E-mail: kwyang@dirams.re.kr

E-mail:kyuh33@dirams.re.kr

Key words: breast cancer stem cell, sorafenib, radiation, hypoxia treatments for patients with breast cancer, as most treatments with radiotherapy and chemotherapy fail, and recurrence and metastasis often occur. Therefore, it is crucial to discover new therapies than can reduce breast cancer mortality. General conventional therapy does not kill all tumor cells and a small side population of cells, which are resistant to radiation and drugs, might be the origin of recurrence and metastasis. These cells are referred to as cancer stem cells (CSCs) (1), and are tumor initiating cells that propagate tumors phenotypically similar to the parental tumor.

Breast CSCs have been isolated by sorting CD $44^{+} \mathrm{CD} 24^{-/ \text {low }}$ cells to initiate the process of carcinogenesis in NOD/SCID mice (2). Tumor growth, invasion, and metastasis depend on the properties of CSCs and their interactions with the tumor microenvironment (3). The importance of the tumor niche has been highly recognized. Among numerous factors to explore tumor microenvironments known to associate with aggressive CSCs (4), hypoxia is believed to be crucial and promotes aggressive tumor phenotypes (5). Oxygen tension is an important signal to induce the low-oxygen CSC population associated with maintaining undifferentiated cells (6). The expression levels of hypoxia-related proteins, including hypoxia-inducible factor- $1 \alpha(\mathrm{HIF}-1 \alpha)$, mediate the increase in the number of CSCs under hypoxic conditions (7). Theoretically, CSCs can be induced by anti-angiogenic therapies under hypoxia, conferring radioresistance to the CSCs, although this has yet to be demonstrated in vivo, and its clinical significance remains unknown.

Therefore, hypoxia-induced stimulation of CSCs might limit the effectiveness of radiotherapy and chemotherapy. These studies suggest that radiotherapy and chemotherapy might have to be combined with cancer stem cell-targeting strategies to improve patient recovery (7).

Sorafenib is an oral multikinase inhibitor $(8,9)$ that blocks tumor cell proliferation and angiogenesis by inhibiting a Raf serine/threonine kinase and vascular endothelial growth factor (VEGF) receptors (10). Sorafenib is currently being used in clinics to treat patients with advanced renal cell carcinoma (RCC) and hepatocellular carcinoma (HCC) $(11,12)$. Eliminating the $\mathrm{CD} 44^{+} \mathrm{CD} 24^{-/ \text {low }}$ cell population from breast cancer cells occurs by inhibiting RAF- $\beta$-catenin activation in vitro (13). In addition, sorafenib effectively reduces melanoma, breast, colon, and lung cancer in vivo $(10,14)$. 
Sorafenib increases HIF-1 $\alpha$ expression in melanoma cells (15); however, the anticancer mechanism of sorafenib combined with ionizing radiation has yet to be investigated. In the present study, we examined the efficacy of sorafenib and radiation against breast cancer and CSCs in non-metastatic MCF-7 and metastatic MDA-MB-231 cells. We demonstrated that a combination of sorafenib and radiation more effectively eliminates CSCs, which might be reflected by the inhibition of HIF-1 $\alpha$ expression from metastatic MDA-MB-231 cells rather than non-metastatic MCF-7 cells under hypoxic conditions. Collectively, our results demonstrated that sorafenib and radiation can be successfully combined to potentiate anti-CSC and anti-angiogenesis activities.

\section{Materials and methods}

Cell culture. The human breast cancer cell lines MDA-MB-231 and MCF-7 were obtained from the American Type Culture Collection (Rockville, MD, USA) and maintained in DMEM (Welgene, Daegu, Korea) supplemented with sodium pyruvate (1 mM), 10\% fetal bovine serum (FBS; HyClone, Logan, UT, USA), and $2 \%$ penicillin/streptomycin (Gibco, Carlsbad, CA, USA). Cells were cultured at $37^{\circ} \mathrm{C}$ in a humidified atmosphere of $5 \% \mathrm{CO}_{2}$. Cells were maintained under hypoxic conditions in a glove box-type anaerobic chamber (Thermo Forma, Marietta, $\mathrm{OH}, \mathrm{USA})$. The hypoxic atmosphere was $<1 \% \mathrm{O}_{2}$, $5 \% \mathrm{CO}_{2}, 10 \% \mathrm{H}_{2}$, and $85 \% \mathrm{~N}_{2}$ with continuous computerized monitoring, indicating a partial $\mathrm{O}_{2}$ pressure of $<15 \mathrm{~mm} \mathrm{Hg}$ at $37^{\circ} \mathrm{C} . \mathrm{O}_{2}$-dependent experiments were performed in both hypoxic and normoxic incubators. Cells were irradiated with 10 Gy using a calibrated ${ }^{137} \mathrm{Cs} \gamma$-ray source (BioBeam 8000, STS, Braunschweig, Germany). All media were changed every 3 days.

Antibodies and reagents. Antibody against MMP-2 was obtained from Santa Cruz Biotechnology, Inc. (Santa Cruz, CA, USA). HIF-1 $\alpha$ antibody was purchased from Abcam (London, UK). Anti- $\beta$-actin antibody was purchased from Sigma-Aldrich (St. Louis, MO, USA) and was incubated with specific horseradish peroxidase-conjugated secondary antibodies (Invitrogen, Carlsbad, CA, USA). Sorafenib was purchased from LC Laboratories (Woburn, MA, USA) and solubilized in DMSO. DMSO was used in all experiments as a vehicle control. Mammospheres were cultured in serum-free MammoCult medium (Stem Cell Technologies, Vancouver, BC, Canada) containing $0.9 \%$ methylcellulose to prevent cell aggregation. Cells were harvested at various time points, fixed in $70 \%$ ethanol, and stained with $40 \mu \mathrm{g} / \mathrm{ml}$ propidium iodide (PI) in the presence of $50 \mu \mathrm{g} / \mathrm{ml}$ RNase A. Cell viability was determined using Thiazolyl Blue tetrazolium bromide (Sigma-Aldrich).

Cell viability assay. MTT assay was conducted using a Thiazolyl Blue tetrazolium bromide and was based on the conversion of MTT to MTT-formazan by mitochondria. MCF-7 and MDA-MB-231 cells were resuspended and plated in 96-well plates at $1 \times 10^{4}$ cells/200 $\mu \mathrm{l}$ in culture media with $5 \%$ FBS. Cells were incubated with or without drugs for 24-72 $\mathrm{h}$ then incubated with MTT $(5 \mathrm{mg} / \mathrm{ml}$ in phosphatebuffered saline; PBS) for $3 \mathrm{~h}$. The plate was then centrifuged at 2,000 rpm for $5 \mathrm{~min}$ at $4^{\circ} \mathrm{C}$, and the MTT solution was removed from the wells by aspiration. The formazan crystals were dissolved in $2 \mathrm{ml}$ of DMSO. The absorbance was recorded on a Paradigm Detection spectrophotometer (Beckman Coulter, Inc., Fullerton, CA, USA) at a wavelength of $540 \mathrm{~nm}$.

Cell proliferation and apoptosis analysis. Live cell numbers were counted with the ADAM-MC automated cell counter (Digital Bio, NanoEnTek Inc., Seoul, Korea). After a 72-h treatment, the cell counter measured total cell numbers, dead cell numbers, and cell viability using two sensitive fluorescence dye staining solutions, AccuStain Solution T (PI/lysis solution) and AccuStain Solution N (PI/PBS). AccuStain Solution $\mathrm{T}$ permeabilizes the plasma membrane and stains the nucleus, which allows total cell enumeration measurements, whereas AccuStain Solution N exclusively stains non-viable cells. A 532-nm optic laser was automatically focused on the cell suspension contained in a disposable microchip, and the cell analysis was conducted with a CDD camera. The Annexin V/PE Apoptosis Detection kit (BD Biosciences, Bedford, MA, USA) was used to assess Annexin V-positive cells. Briefly, fresh cell preparations were incubated with $1 \mathrm{X}$ Annexin binding buffer and Annexin V/PE $(2.5 \mu \mathrm{g} / \mathrm{ml})$-conjugated primary antibody and 7-AAD $(5 \mu \mathrm{l})$ for $15 \mathrm{~min}$ on ice. Following incubation, PI $(10 \mu \mathrm{g} / \mathrm{ml})$ was added to the suspension, and the cells were analyzed by FACSAria (BD Biosciences, San Jose, CA, USA).

Cell cycle analysis. Cells were treated with $5 \mu \mathrm{g} / \mathrm{ml}$ sorafenib or $10 \mathrm{~Gy}$ radiation for $24 \mathrm{~h}$ and harvested. The cells were trypsinized and resuspended in $3 \mathrm{ml}$ PBS. Cells were centrifuged and washed in $3 \mathrm{ml}$ PBS. Following fixation in $70 \%$ ethanol for $16 \mathrm{~h}$ at $-20^{\circ} \mathrm{C}$, the cells were stained with PI $(40 \mu \mathrm{g} / \mathrm{ml})$ and RNAse A $(50 \mu \mathrm{g} / \mathrm{ml})$ prior to analysis. The stained cells were subjected to cell cycle analysis using FACSAria.

FACS sorting and analysis. Cells ( $1 \times 10^{6}$ cells) were incubated with anti-CD44-APC and anti-CD24-FITC antibodies (BD Biosciences) at $2 \mu \mathrm{g} / \mathrm{ml}(1: 10)$ in the dark, on ice, for $15 \mathrm{~min}$ (MDA-MB-231) or $1 \mathrm{~h}$ (MCF-7), washed twice with cold PBS, then resuspended in PBS $(0.5 \mathrm{ml}) . \mathrm{CD}_{4} 4^{+} \mathrm{CD} 24^{-}$and $\mathrm{CD} 44^{-}$ $\mathrm{CD} 24^{+}$cells were identified and isolated from MDA-MB-231 and MCF-7 cells using a FACSAria instrument.

Mammosphere formation. Cells were suspended at MCF-7 $(5,000$ cells $/ \mathrm{ml})$ and MDA-MB-231 $(600$ cells $/ \mathrm{ml})$ in primary mammosphere formation and MCF-7 (1,000 cells/ml) and MDA-MB-231 (300 cells $/ \mathrm{ml})$ in secondary mammosphere formation in complete Mammocult media (Stem Cell Technologies) and plated in triplicate wells on a 24-well ultra-low attachment culture plate (Corning Inc., Corning, NY, USA). Cells were incubated at $37^{\circ} \mathrm{C}$ for $7-10$ days. The number of mammospheres was imaged by inverted microscopy (Nikon Eclipse TS 100, Tokyo, Japan) and mammosphere diameters were determined using Image-Pro Plus 7.0 software. The primary mammosphere formation culture was exposed to sorafenib $(5 \mu \mathrm{g} / \mathrm{ml})$ and radiation (10 Gy), whereas the second passage was cultured in the absence of sorafenib and radiation. Mammospheres were collected at the second passage by gentle centrifugation $(800 \mathrm{rpm})$ and dissociated enzymatically (10 min in $0.05 \%$ trypsin, $0.53 \mathrm{mM}$ EDTA) and mechanically. 
The dissociated cells were plated in a 24-well ultra-low attachment plate and cultured for 7-10 days.

Immunocytochemistry. Collected cell fractions from FACS were counted and cytospun onto glass slides at 1,000 cells per spot with a Cytospin 4 cytospinner (Thermo Scientific, Waltham, MA, USA). Cells were fixed in $4 \%$ paraformaldehyde and stained overnight at $4{ }^{\circ} \mathrm{C}$ with primary antibodies directed against HIF-1 $\alpha$ (1:500) followed by secondary antibodies (1:1000 Texas Red conjugated anti-mouse and antirabbit $\mathrm{H}+\mathrm{L}$ IgG; Vector Laboratories, Burlingame, CA, USA) for $1 \mathrm{~h}$ at room temperature. Nuclei were counterstained with 4',6-diamidino-2-phenylindole, and images were captured with a fluorescent microscope (Nikon Eclipse 80i).

Western blotting. Cells were harvested with ice-cold PBS, and re-suspended in lysis buffer containing (mM) 20 Tris- $\mathrm{HCl}$ (pH 7.5), $150 \mathrm{NaCl}, 1 \mathrm{Na}_{2}$ EDTA, 1 EGTA, $1 \%$ Triton, 2,5 sodium pyrophosphate, $1 \beta$-glycerophosphate, $1 \mathrm{Na}_{3} \mathrm{VO}_{4}, 1 \mu \mathrm{g} / \mathrm{ml}$ leupeptin and $1 \mathrm{mM}$ phenylmethanesulfonyl fluoride. Extracts were diluted in a mix of LDS sample buffer and heated at $95^{\circ} \mathrm{C}$ for $5 \mathrm{~min}$. Samples were electrophoresed on $10 \%$ sodium dodecyl sulfate-polyacrylamide gels (Invitrogen) and transferred onto nitrocellulose membranes (GE Healthcare Life Sciences, Piscataway, NJ, USA). The blots were saturated in TBS-T buffer (20 mM Tris, $137 \mathrm{mM} \mathrm{NaCl}, 0.05 \%$ Tween-20, $\mathrm{pH}$ 7.6), containing $3 \% \mathrm{BSA}$ for $1 \mathrm{~h}$ at room temperature, incubated overnight at $4{ }^{\circ} \mathrm{C}$ with primary antibodies: antiVEGF (1:500; Santa Cruz Biotechnology Inc.), anti-HIF-1 $\alpha$ (1:500; Abcam), anti- $\beta$-actin (1:5,000; Sigma-Aldrich) and subsequently incubated with specific horseradish peroxidaseconjugated secondary antibodies. The immunoreactive proteins were detected using enhanced chemiluminescence (Thermo Scientific, Rockford, IL, USA). Immunoblots were quantified using the ImageMaster densitometry program.

Statistical analysis. The paired Student's t-test and Microsoft Excel were used for the MTT assays, cell proliferation, mammosphere formation, and FACS data, which were conducted in triplicate and repeated three times. Percent inhibition of the western blot data was determined from the ratio of band density. p-value $<0.05$ was considered to indicate a statistically significant difference.

\section{Results}

Sorafenib and radiation inhibit proliferation and induce breast cancer cell apoptosis. To investigate the effect of sorafenib and radiation on MDA-MB-231 and MCF-7 cells, we first examined the potential to inhibit cell growth by sorafenib and radiation using MTT and apoptosis assays. Sorafenib and radiation treatment resulted in a dose-dependent inhibition of cell viability, with an $\mathrm{IC}_{50}$ of $5 \mu \mathrm{g} / \mathrm{ml}$ for sorafenib and $10 \mathrm{~Gy}$ of radiation in both cell lines (Fig. 1A). Furthermore, the effect of combining sorafenib and radiation was evaluated by Annexin V/PE apoptosis assay after $72 \mathrm{~h}$ of treatment. Cells negative for 7-AAD and positive for Annexin $\mathrm{V}$ were regarded as cells early in apoptosis (Annexin V+, 7-AAD-); 7-AAD-positive cells, which bind Annexin V, were defined as late apoptotic cells (Annexin $\mathrm{V}+, 7-\mathrm{AAD}+$ ); 7-AAD-positive cells that did not bind Annexin $\mathrm{V}$ were considered necrotic cells (Annexin V-, 7-AAD+). The combined treatment of sorafenib and radiation in MDA-MB-231 cells significantly increased the antitumor effect of radiation alone or sorafenib alone at $21 \% \mathrm{O}_{2}$ (normoxia). Late apoptotic cells were observed in the combined treatment group $(30.1 \pm 3.5 \%)$ compared with apoptotic cells in the sorafenib $(2.9 \pm 0.5 \%)$ and radiation $(9.8 \pm 0.9 \%)$ treatment groups at $1 \% \mathrm{O}_{2}$ (hypoxia) (Fig. 1B). However, the combined treatment increased subsequent necrosis $(42.5 \pm 2.5 \%)$ and it moderately increased late apoptosis $(34.5 \pm 1.2 \%)$ in comparison with sorafenib or radiation treatment alone at $1 \% \mathrm{O}_{2}$ (Fig. 1B). Hypoxia may have induced more necrosis through the effect of combined treatment in both cell lines, unlike normoxia. Similarly, early apoptotic MCF-7 cells increased under normoxia rather than under hypoxia but apoptotic cells were not clearly observed in the combined treatment group as compared with apoptotic cells in the sorafenib and radiation treatment groups under normoxia or hypoxia (Fig. 1B). These data suggest a potential synergistic effect of the combined treatment on MDA-MB-231 cells but not on MCF-7 cells. Similar results were observed in athymic nude mice bearing subcutaneously transplanted MDA-MB-231 cells (data not shown).

To determine the effect of sorafenib and radiation on cell cycle distribution, cells were synchronized by $24 \mathrm{~h}$ stabilization prior to the different treatments. After $24 \mathrm{~h}$ of treatment, G2/M arrest was observed in a flow cytometry cell cycle analysis with the combined treatment resulting in $28 \pm 1.1 \%$ (MDA-MB-231) and $32.5 \pm 0.6 \%$ (MCF-7) of the cell population compared with the control group and the single treatments (Fig. 1C).

Combination of sorafenib and radiation inhibits breast CSCs in vitro. To evaluate whether the combination of sorafenib and radiation treatment could suppress breast CSCs in vitro under normoxic and hypoxic conditions, both cell lines were treated with $5 \mu \mathrm{g} / \mathrm{ml}$ of sorafenib alone, $10 \mathrm{~Gy}$ of radiation alone, or a combined treatment for $72 \mathrm{~h}$. We assessed expression of the prospective CSC markers CD44-APC and CD24-FITC by flow cytometry. The basal cell line, MDA-MB-231 cells, showed a significantly decreased percentage of CD $44^{+} \mathrm{CD} 24^{-/ \text {low }}$ cells during co-treatment with sorafenib and radiation $(42 \pm 1.5 \%)$ compared to that in the sorafenib alone $(72 \pm 1.6 \%)$ and radiation alone $(59 \pm 4 \%)$ groups under hypoxic conditions, whereas no significant difference was observed under normoxic conditions (Fig. 2A).

Conversely, the luminal cell line MCF-7 showed a reduced percentage of $\mathrm{CD} 44^{+} \mathrm{CD} 24^{-/ \text {low }}$ cells during co-treatment with sorafenib and radiation $(0.06 \pm 0.1 \%)$ rather than sorafenib alone $(5 \pm 0.5 \%)$ and radiation alone $(1.37 \pm 0.01 \%)$ under normoxic conditions, whereas no significant difference was observed under hypoxic conditions (Fig. 2A). Thus, our data suggest that the synergistic efficacy of co-treatment with sorafenib and radiation resulted in a potential combined treatment effect for specific targeting of CD $44^{+} \mathrm{CD} 24^{- \text {/low }}$ cells from breast cancer cells in vitro.

A small population of breast cancer cells and mammary stem cell-like/progenitor cells are enriched in floating spherical clusters of cells (16). These properties, based on self-renewal ability, exhibit serial mammosphere formation and differentiation into multiple lineages (16). To confirm whether the 

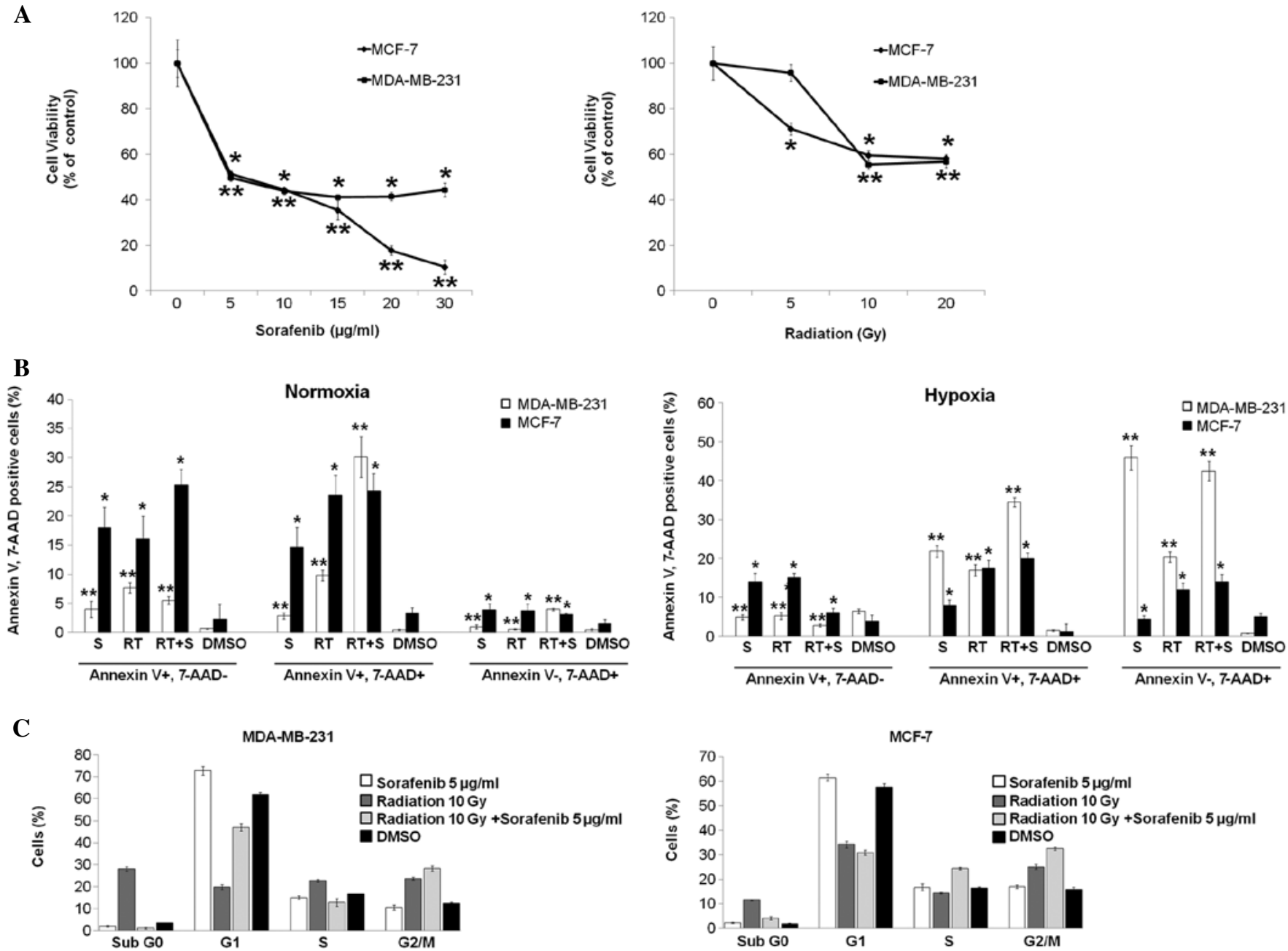

Figure 1. Combination of radiation and sorafenib induces synergistic apoptosis and G2/M cell cycle arrest in breast cancer cells. (A) MDA-MB-231 and MCF-7 cells $\left(1 \times 10^{4}\right.$ cells/well) were seeded in 96-well microplates and treated with increasing doses of radiation and concentrations of sorafenib as indicated. After $72 \mathrm{~h}$ (radiation) and $48 \mathrm{~h}$ (sorafenib) of incubation, respectively, cell viability was assessed by the MTT assay, and the concentration that induced 50\% growth inhibition $\left(\mathrm{IC}_{50}\right.$ ) was determined to be of $\sim 10 \mathrm{~Gy}$ radiation and $5 \mu \mathrm{g} / \mathrm{ml}$ sorafenib for both cell lines. (B) Cells were treated with radiation (RT, $10 \mathrm{~Gy}$ ), sorafenib $(\mathrm{S}, 5 \mu \mathrm{g} / \mathrm{ml})$, radiation + sorafenib (RT $+\mathrm{S}, 10 \mathrm{~Gy}+5 \mu \mathrm{g} / \mathrm{ml}$ ) or DMSO. After $72 \mathrm{~h}$, the percentage of Annexin V/PE-positive cells was quantified using flow assisted cell sorting. (C) Cells were treated with radiation (RT, $10 \mathrm{~Gy}$ ), sorafenib (S, $5 \mu \mathrm{g} / \mathrm{ml})$, radiation + sorafenib (RT $+\mathrm{S}, 10 \mathrm{~Gy}+5 \mu \mathrm{g} / \mathrm{ml})$ or DMSO for $24 \mathrm{~h}$ and analyzed by flow cytometry for the cell cycle analysis. Mean percentages \pm standard deviation (SD) of cells in each cycle phase are shown. Data are means of three separate experiments ${ }^{*} \mathrm{p}<0.001,{ }^{* *} \mathrm{p}<0.01$.

combination of sorafenib and radiation could more effectively suppress mammosphere formation than single treatments such as reduction of $\mathrm{CD} 44^{+} \mathrm{CD} 24^{- \text {/low }}$ cells from co-treated breast cancer cells, cells were cultured in radiation (10 Gy), sorafenib $(5 \mu \mathrm{g} / \mathrm{ml})$, radiation + sorafenib $(10 \mathrm{~Gy}+5 \mu \mathrm{g} / \mathrm{ml})$ or DMSO in ultra-low attachment plates and then cultured to the secondary passage in the absence of sorafenib and radiation under normoxic and hypoxic conditions. The combination of sorafenib and radiation inhibited the formation of primary mammospheres under both normoxic and hypoxic conditions (Fig. 2B), whereas these treatments increased the formation of primary mammospheres in MCF-7 cells under hypoxic conditions. The percentage of secondary mammospheres formed decreased significantly in MDA-MB-231 cells under the hypoxic conditions but not under normoxia $(\mathrm{p}<0.001)$ (Fig. 2B). The number of mammospheres was reduced by 1.5-87.5-fold (MDA-MB-231 cells) and 1-2.1-fold (MCF-7 cells) $(\mathrm{p}<0.05)$ but also the size of both primary (Fig. $2 \mathrm{~B}$ and C) and secondary mammospheres (data not shown) decreased compared to those in single treatments. These results demonstrate that the combined treatment of sorafenib and radiation was able to preferentially target breast CSCs.

Combination of sorafenib and radiation inhibits HIF- $1 \alpha$ expression associated with highly activated $\mathrm{CD}_{4} 4^{+} \mathrm{CD} 24^{- \text {-low }}$ cells. The sorted $\mathrm{CD} 44^{+} \mathrm{CD} 24^{- \text {llow }}$ cells and $\mathrm{CD} 44^{-} \mathrm{CD} 24^{+}$ cells were further examined by immunocytochemistry to explore whether increased HIF-1 $\alpha$ expression in CSCs is associated with targeting of CSCs by the combination of sorafenib and radiation (Fig. 3A). Additionally, after treatment with radiation (10 Gy), sorafenib (5 and $10 \mu \mathrm{g} / \mathrm{ml}$ ), radiation + sorafenib $(10 \mathrm{~Gy}+5 \mu \mathrm{g} / \mathrm{ml}$ and $10 \mathrm{~Gy}+10 \mu \mathrm{g} / \mathrm{ml})$ or DMSO for $72 \mathrm{~h}$, immunoblotting of breast cancer cells under hypoxic and normoxic conditions showed different HIF-1 $\alpha$ expression patterns (Fig. 3B and C). HIF-1 $\alpha$ was aberrantly expressed in the sorted $\mathrm{CD} 44^{+} \mathrm{CD} 24^{- \text {llow }}$ cells but not in the sorted CD $44^{-} \mathrm{CD} 24^{+}$cells (Fig. 3A). As shown in Fig. 3B and $\mathrm{C}$, the combination of sorafenib and radiation appeared 
A
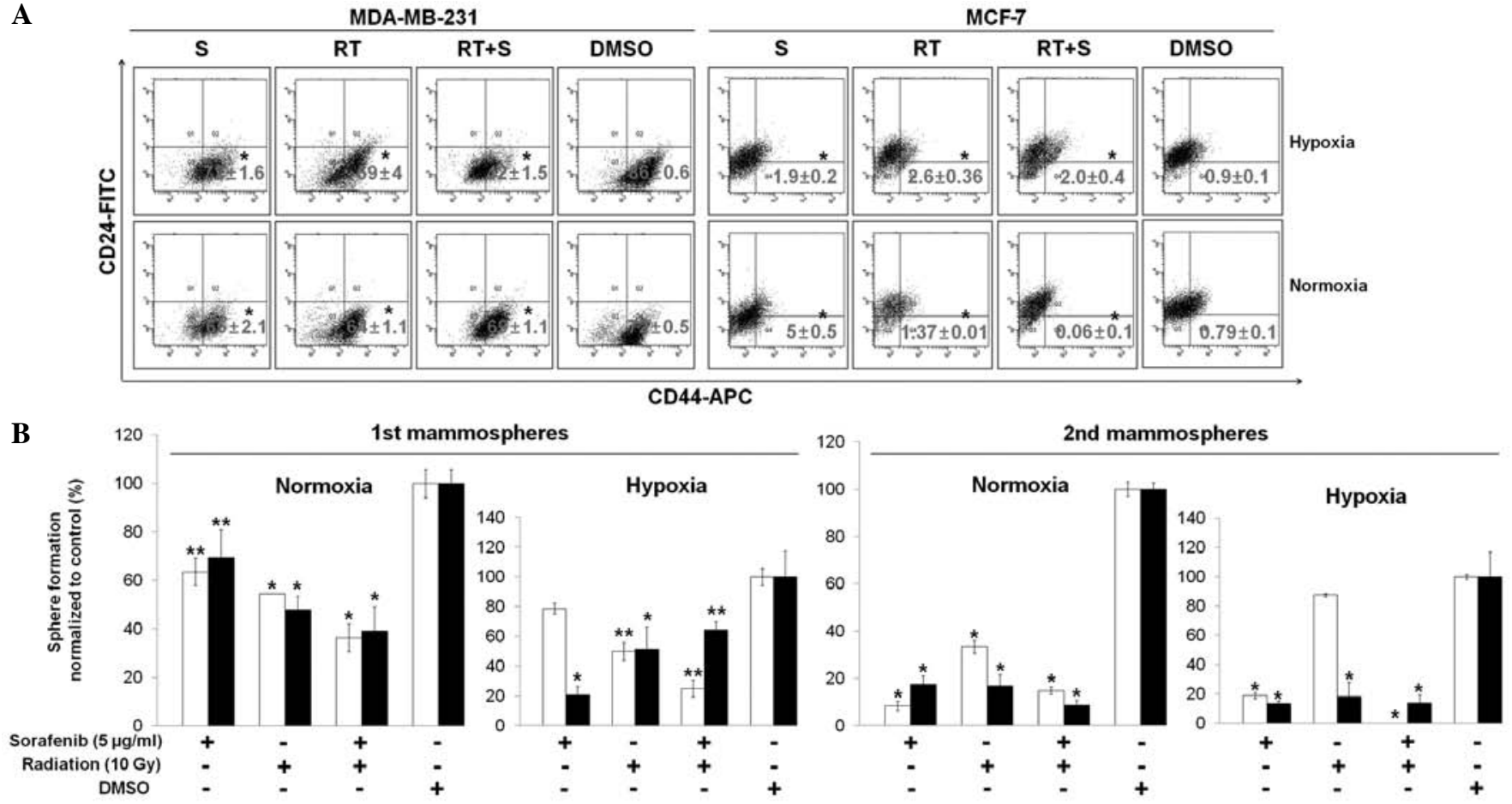

C
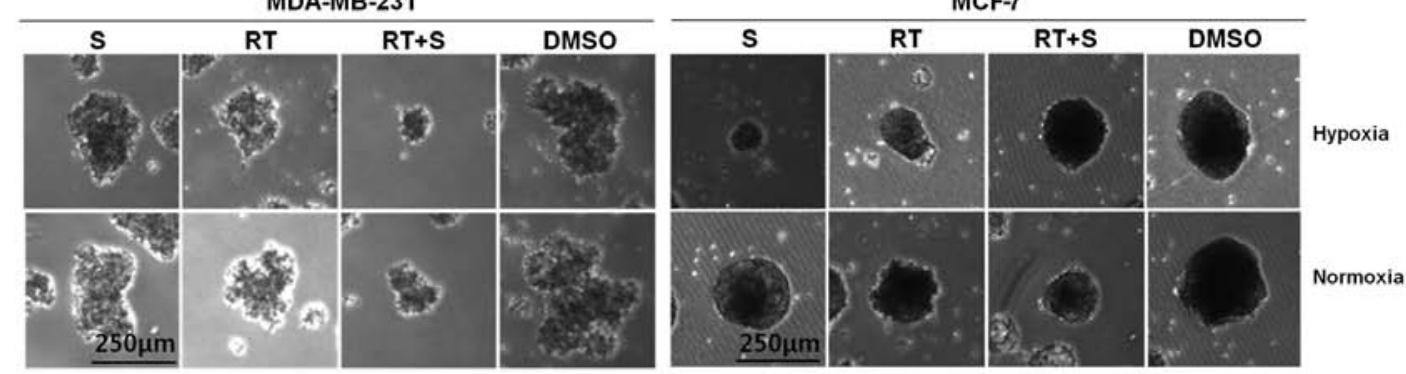

Figure 2. Combination of sorafenib and radiation inhibits the $\mathrm{CD} 44^{+} \mathrm{CD} 24^{- \text {llow }}$ cell population and mammosphere formation. (A) MDA-MB-231 and MCF-7 cells were treated with or without sorafenib $\left(\mathrm{S}, 5 \mu \mathrm{g} / \mathrm{ml}\right.$ ) combined with radiation (RT, $10 \mathrm{~Gy}$ ) under $21 \% \mathrm{O}_{2}$ (normoxia) or $1 \% \mathrm{O}_{2}$ (hypoxia). After $72 \mathrm{~h}$, a flow assisted cell sorting analysis was conducted using specific surface markers for basal (CD44-APC) and luminal (CD24-FITC) epithelial cells and the percentage of cells $\left(\mathrm{CD} 44^{+} \mathrm{CD} 24^{-/ \mathrm{low}}\right)$ of each cell line was evaluated in three independent experiments. (B) Cells were seeded to form primary mammospheres at a density of MCF-7 (5,000 cells $/ \mathrm{ml})$ and MDA-MB-231 (600 cells $/ \mathrm{ml})$ and secondary mammospheres at a density of MCF-7 (1,000 cells/ml) and MDA-MB-231 (300 cells/ml). Additionally, primary mammospheres were incubated with radiation (RT, $10 \mathrm{~Gy}$ ), sorafenib (S, $5 \mu \mathrm{g} / \mathrm{ml})$, radiation + sorafenib (RT $+\mathrm{S}, 10 \mathrm{~Gy}$ $+5 \mu \mathrm{g} / \mathrm{ml}$ ) or DMSO for 7-10 days, whereas secondary mammospheres were not treated with radiation or sorafenib under hypoxia or normoxia for 7-10 days. White and black bars indicate MDA-MB-231 and MCF-7 cells, respectively. Data are means of three separate experiments; bar, standard deviation (SD). ${ }^{*} \mathrm{p}<0.001,{ }^{* *} \mathrm{p}<0.05$. (C) Representative images from primary mammospheres.

to significantly reduce HIF-1 $\alpha$ expression in MDA-MB-231 cells under hypoxia but was slightly decreased in MCF-7 cells under hypoxia compared to that from sorafenib or radiation alone, whereas these effects resulted in no difference under normoxia (Fig. 3B and C). Therefore, we suggest that inhibition of HIF-1 $\alpha$ by sorafenib and radiation may eliminate breast CSCs under hypoxic conditions.

Combination of sorafenib and radiation effectively inhibits matrix metalloproteinase-2 (MMP-2) activity in metastatic $M D A-M B-231$ cells. MMP-2 is well recognized for its role in tumorigenesis. Studies have shown that inhibiting MMP-2 activity reduces the metastatic potential of malignant cells and MMP-2 downregulation leads to decreased tumor cell invasion (17-21).

We performed immunoblotting studies to investigate whether a decrease in MMP-2 could be correlated with the efficacy of combined effect of sorafenib and radiation in breast cancer. MMP-2 expression in MDA-MB-231 cells decreased in response to the combined treatment under normoxia but not under hypoxia, whereas no differences were observed in MCF-7 cells (Fig. 4A and B).

\section{Discussion}

The anticancer efficacy of chemotherapy and radiotherapy has been evaluated in various types of cancer. However, although patients with breast cancer are treated by chemotherapy or radiotherapy, CSCs, a side population of the bulk tumor responsible for initiating and self-renewing tumor, cause relapse and metastasis and eventually give rise to new tumors (22). Therefore, we determined if the combination of sorafenib and radiation induced anti-CSC activity under hypoxia in breast cancer cells. The anticancer efficacy of 
A
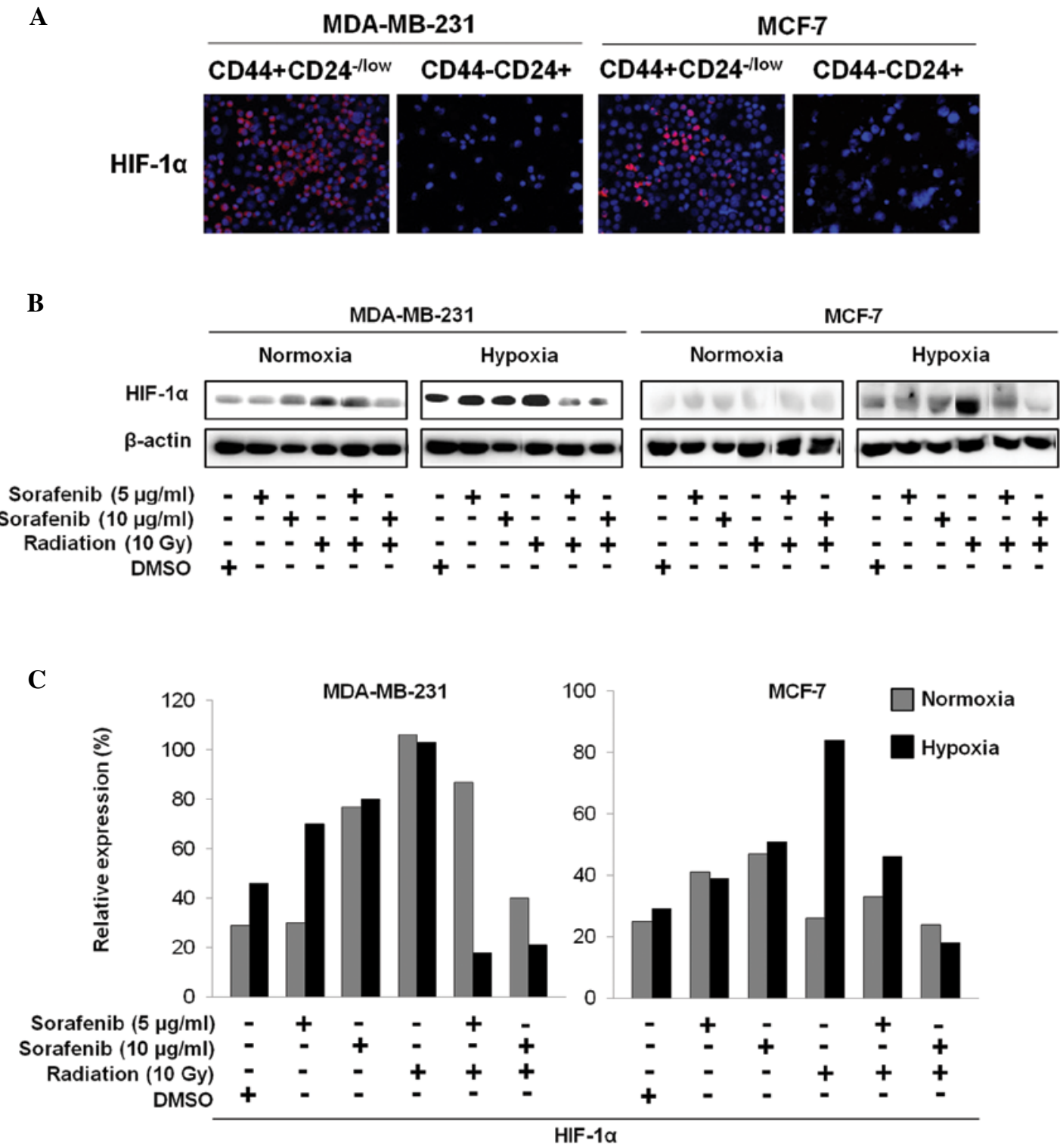

Figure 3. Hypoxia inducible factor (HIF)- $1 \alpha$ from CD $44^{+} \mathrm{CD} 24^{-/ 10 w}$ cells was highly induced and the combination of sorafenib and radiation blocked $\mathrm{HIF}-1 \alpha$ in MDA-MB-231 cells under hypoxic conditions. (A) $\mathrm{CD} 44^{+} \mathrm{CD} 24^{-/ 10 w}$ cells were sorted by flow cytometry. Then, sorted cells were cytospun, fixed, permeabilized and immunostained with antibodies to HIF-1 $\alpha$ and vascular endothelial growth factor (VEGF). (B) Cells were treated with radiation (RT, 10 Gy), sorafenib $(\mathrm{S}, 5 \mu \mathrm{g} / \mathrm{ml})$, radiation + sorafenib (RT $+\mathrm{S}, 10 \mathrm{~Gy}+5 \mu \mathrm{g} / \mathrm{ml})$ or DMSO for $72 \mathrm{~h}$. Cells were lysed and protein expression was detected by western blotting. (C) Quantification of the results from western blotting shown in (B) (normalized by the $\beta$-actin value).

sorafenib combined with radiation can be partially determined by cell cycle arrest. Sorafenib, which leads to a G1 block by inhibiting the mitogen activated protein kinase pathway, causes no obvious arrest in the majority of asynchronous cell lines, but it causes cell cycle arrest in some cell lines (23). In MDA-MB-231 and MCF-7 cells, we showed that sorafenib alone might not affect cell cycle arrest but that a combination with radiation induces $\mathrm{G} 2 / \mathrm{M}$ arrest. Additionally, a high concentration of sorafenib is associated with inducing apoptosis via the mitochondrial intrinsic pathway and inhibits cell proliferation (24). We showed that sorafenib in combination with radiation synergistically induced apoptosis (early and late apoptosis) in MDA-MB-231 cells (5.5 and 30.1\%) and MCF-7 cells (25.3 and $24.3 \%$ ) compared to sorafenib alone (4 and $2.9 \%$ ) and radiation alone (7.7 and 9.8\%) in MDA-MB-231 cells, and sorafenib alone (18 and 14.7\%) and radiation alone (16.1 and 23.5\%) in MCF-7 cells under normoxia. Sorafenib may be associated with the induction of necrosis rather than apoptotic cell death, and sorafenib in combination with radiation increased late apoptosis in MDA-MB-231 cells under hypoxic conditions. Cancer cells more resistant to hypoxia show that low $\mathrm{O}_{2}$ tension induces apoptosis as well as necrosis and completely prevents apoptosis by Bcl-2 and Bcl-X (25). However, apoptosis and necrosis were not observed in MCF-7 cells in response to the combined sorafenib and radiation treatment under hypoxia in vitro.

Sorafenib has been clinically used in treatment for RCC, HCC, and thyroid cancer $(12,26,27)$. Sorafenib alone is insufficient for inhibiting tumors in a colorectal carcinoma (HT29/tk-luc)-bearing animal model compared with radiation alone (28). Instead of treatment of sorafenib alone or radiation alone, a combination with sorafenib and radiation may be successfully used for treating advanced RCC (29). Similar results were also observed in metastatic MDA-MB-231 cell- 
A
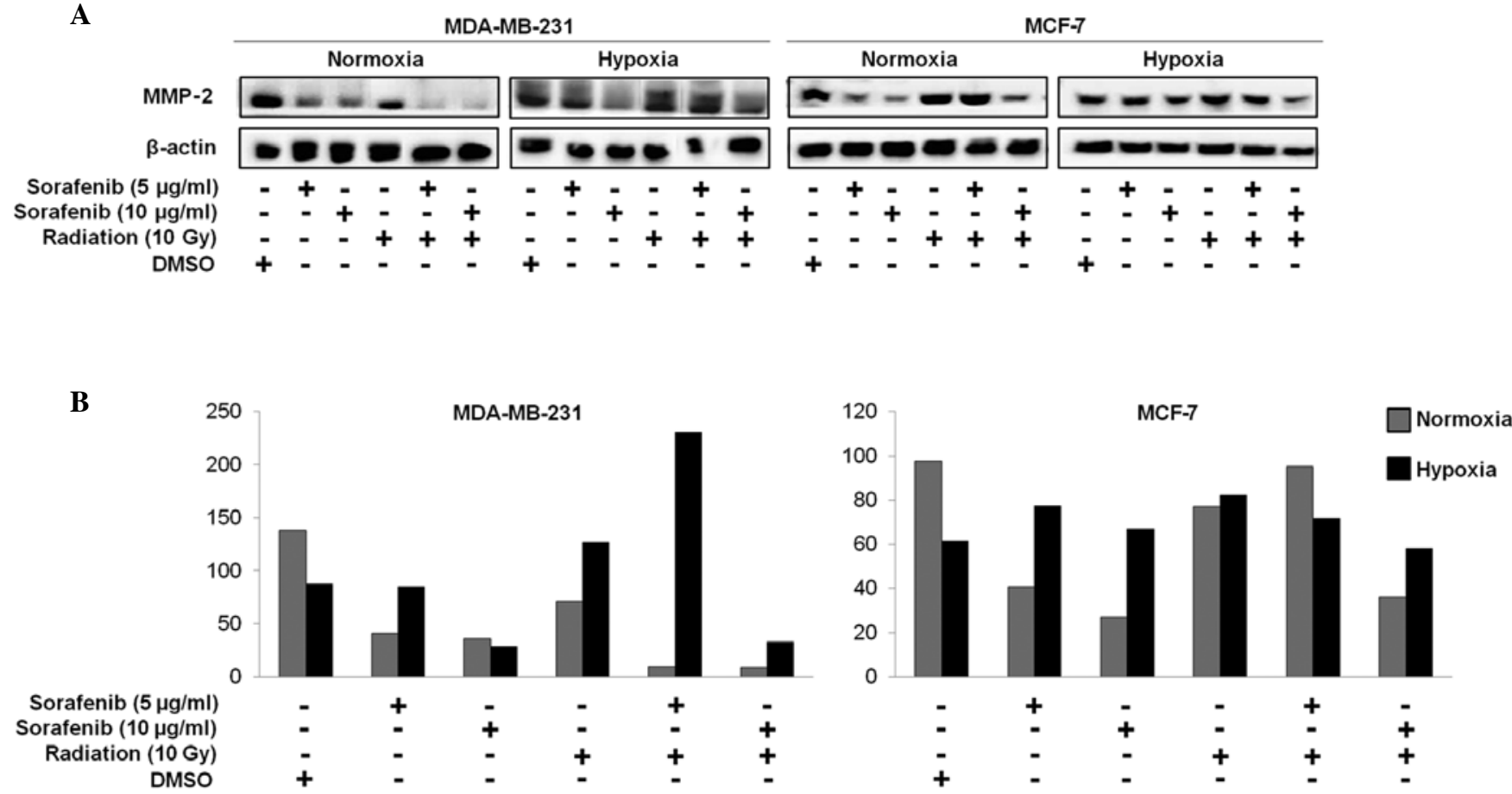

Figure 4. Combination of sorafenib and radiation highly reduced MMP-2 secretion from metastatic MDA-MB-231 rather than from non-metastatic MCF-7 breast cancer cells. (A) Cells were treated with radiation (RT, $10 \mathrm{~Gy}$ ), sorafenib (S, $5 \mu \mathrm{g} / \mathrm{ml}$ ), radiation + sorafenib (RT $+\mathrm{S}, 10 \mathrm{~Gy}+5 \mu \mathrm{g} / \mathrm{ml}$ ) or DMSO for $72 \mathrm{~h}$. The cells were lysed and protein expression was detected by western blotting. (B) Quantification of the results from western blotting shown in (A) (normalized by the $\beta$-actin value).

bearing athymic nude mice (data not shown). Human breast cancer cells develop an increased CSC population under hypoxic conditions (7). Hypoxia-induced HIF-1 $\alpha$ reduces migration potential and sphere formation in glioma cells and expansion of CD133 ${ }^{+}$CSCs in glioblastoma $(30,31)$.

Sorafenib eliminates EZH-induced BTIC expansion, decreases the number of $\mathrm{CD} 44^{+} \mathrm{CD} 24^{-/ \text {low }}$ cells, and blocks the formation of precancerous mammospheres in human breast cancer cells (13). These observations are consistent with our result that a combination of sorafenib and radiation produced synergistic inhibition of CD $44^{+} \mathrm{CD} 24^{-/ \text {low }}$ cells in basal breast cancer cells (MDA-MB-231 cells) under hypoxic conditions. Furthermore, we demonstrated that the combination of sorafenib and radiation significantly suppressed mammosphere formation in MDA-MB-231 cells but not in MCF-7 cells under both hypoxic and normoxic conditions. The mechanism of suppressing breast CSCs by the combination of sorafenib and radiation is unknown, however, our results suggest that the combination of sorafenib and radiation is not cytotoxic to non-CSCs, and preferentially cytotoxic to CSCs. Accumulating evidence indicates that HIF-1 $\alpha$ is significantly correlated with the rate of CSCs that express CD $44^{+} \mathrm{CD} 24^{- \text {-low }}$ in the early stage of breast cancer (32). Thus, HIF-1 $\alpha$ may be a strong candidate for breast CSC-targeting with the combination of sorafenib and radiation.

This is the first in vitro study to demonstrate the efficacy of a combination of sorafenib and radiation for treating breast cancer cells and CSCs. The combination of sorafenib and radiation is a potentially novel strategy to inhibit breast CSCs by reducing HIF-1 $\alpha$ and MMP-2 expression. However, these findings remain to be demonstrated in preclinical and clinical evaluations for breast cancer therapy. Nevertheless, our results clearly show for the first time that the combination of sorafenib and radiation is potentially efficacious for inhibiting breast cancer stem cells in vitro.

\section{Acknowledgements}

This study was supported by the National R\&D Program through the Dongnam Institute of Radiological and Medical Sciences (DIRAMS) funded by the Ministry of Education, Science, and Technology (50593-2012, 50595-2012).

\section{References}

1. Reya T, Morrison SJ, Clarke MF and Weissman IL: Stem cell, cancer and cancer stem cell. Nature 414: 105-111, 2001.

2. Al-Hajj M, Wicha MS, Benito-Hernandez A, Morrison SJ and Clarke MF: Prospective identification of tumorigenic breast cancer cells. Proc Natl Acad Sci USA 100: 3983-3988, 2003.

3. Generali D, Buffa FM, Berruti A, et al: Phosphorylated ERalpha, HIF-1alpha, and MAPK signaling as predictors of primary endocrine treatment response and resistance in patients with breast cancer. J Clin Oncol 27: 227-234, 2009.

4. Hu M and Polyak K: Molecular characterization of the tumour microenvironment in breast cancer. Eur J Cancer 44: 2760-2765, 2008.

5. Heddleston JM, Zhizhong L, McLendon RE, Hjelmeland AB and Rich JN: The hypoxic microenvironment maintains glioblastoma stem cells and promotes reprogramming towards a cancer stem cell phenotype. Cell Cycle 8: 3274-3284, 2009.

6. Xing F, Okuda H, Watabe M, et al: Hypoxia-induced Jagged2 promotes breast cancer metastasis and self-renewal of cancer stem-like cells. Oncogene 30: 4075-4086, 2011.

7. Conley SJ, Gheordunescu E, Kakarala P, et al: Antiangiogenic agents increase breast cancer stem cells via the generation of tumor hypoxia. Proc Natl Acad Sci USA 109: 2784-2789, 2012.

8. Wilhelm SM, Adnane L, Newell P, Villanueva A, Llovet JM and Lynch M: Preclinical overview of sorafenib, a multikinase inhibitor that targets both Raf and VEGF and PDGF receptor tyrosine kinase signaling. Mol Cancer Ther 7: 3129-3140, 2008. 
9. Iyer R, Fetterly G, Lugade A and Thanavala Y: Sorafenib: a clinical and pharmacologic review. Expert Opin Pharmacother 11: 1943-1955, 2010.

10. Wilhelm SM, Carter C, Tang L, et al: BAY 43-9006 exhibits broad spectrum oral antitumor activity and targets the RAF/ MEK/ERK pathway and receptor tyrosine kinases involved in tumor progression and angiogenesis. Cancer Res 64: 7099-7109, 2004.

11. Siegel AB, Olsen SK, Magun A and Brown RS: Sorafenib: Where do we go from here? Hepatology 52: 360-369, 2010.

12. Escudier B, Eisen T, Stadler WM, et al: Sorafenib in advanced clear-cell renal-cell carcinoma. N Engl J Med 356: 125-134, 2007.

13. Chang CJ, Yang JY, Xia W, et al: EZH2 promotes expansion of breast tumor initiating cells through activation of RAF1- $\beta$ catenin signaling. Cancer Cell 19: 86-100, 2011.

14. Sharma A, Trivedi NR,Zimmerman MA, Tuveson DA, Smith CD and Robertson GP: Mutant V599 EB-Raf regulates growth and vascular development of malignant melanoma tumors. Cancer Res 65: 2412-2421, 2005.

15. Kumar SM, Yu H, Edwards R, et al: Mutant V600E BRAF increases hypoxia inducible factor-1alpha expression in melanoma. Cancer Res 67: 3177-3184, 2007.

16. Dontu G, Abdallah WM, Foley JM, et al: In vitro propagation and transcriptional profiling of human mammary stem/progenitor cells. Genes Dev 17:1253-1270, 2003.

17. Ata N, Oku T, Hattori M, Fujii H, Nakajima M and Saiki I: Inhibition by galloylglucose (GG6-10) of tumor invasion through extracellular matrix and gelatinase-mediated degradation of type IV collagens by metastatic tumor cells. Oncol Res 8: 503-511, 1996.

18. Elkin M, Reich R, Nagler A, et al: Inhibition of matrix metalloproteinase- 2 expression and bladder carcinoma metastasis by halofuginone. Clin Cancer Res 5: 1982-1988, 1999.

19. Zervos EE, Shafii AE, Haq M and Rosemurgy AS: Matrix metalloproteinase inhibition suppresses MMP-2 activity and activation of PANC-1 cells in vitro. J Surg Res 84: 162-167, 1999.

20. Denkert C, Siegert A, Leclere A, Turzynski A and Hauptmann S: An inhibitor of stress-activated MAP-kinase reduces invasion and MMP-2 expression of malignant melanoma cells. Clin Exp Metastasis 19: 79-85, 2002.
21. Kargozaran H, Yuan SY, Breslin JW, et al: A role for endothelial-derived matrix metalloproteinase- 2 in breast cancer cell transmigration across the endothelial-basement membrane barrier. Clin Exp Metastasis 24: 495-502, 2007.

22. Eyler CE and Rich JN: Survival of the fittest: Cancer stem cells in therapeutic resistance and angiogenesis. J Clin Oncol 10: 2839-2845, 2008.

23. Plastaras JP, Kim SH, Liu YY, et al: Cell cycle dependent and schedule-dependent antitumor effects of sorafenib combined with radiation. Cancer Res 67: 9443-9454, 2007.

24. Bonelli MA, Fumarola C, Alfieri RR, et al: Synergistic activity of letrozole and sorafenib on breast cancer cells. Breast Cancer Res Treat 124: 79-88, 2010.

25. Shimizu S, Eguchi Y, Kamiike W, et al: Induction of apoptosis as well as necrosis by hypoxia and predominant prevention of apoptosis by Bcl-2 and Bcl-XL. Cancer Res 56: 2161-2166, 1996.

26. Gupta-Abramson V, Troxel AB, Nellore A, et al: Phase II trial of sorafenib in advanced thyroid cancer. J Clin Oncol 26: 4714-4719, 2008

27. Llovet JM, Ricci S, Mazzaferro V, et al: Sorafenib in advanced hepatocellular carcinoma. N Engl J Med 359: 378-390, 2008.

28. Kuo YC, Lin WC, Chiang IT, et al: Sorafenib sensitizes human colorectal carcinoma to radiation via suppression of $\mathrm{NF}-\kappa \mathrm{B}$ expression in vitro and in vivo. Biomed Pharmacother 66: 12-20, 2012.

29. Kasibhatla M, Steinberg P, Meyer J, Ernstoff MS and George DJ: Radiation therapy and sorafenib: Radiation therapy and sorafenib: clinical data and rationale for the combination in metastatic renal cell carcinoma. Clin Genitourin Cancer 5: 291-294, 2007.

30. Soeda A, Park M, Lee D, et al: Hypoxia promotes expansion of the CD133-positive glioma stem cells through activation of HIF-1 $\alpha$. Oncogene 28: 3949-3959, 2009.

31. Méndez O, Zavadil J, Esencay M, et al: Knock down of HIF-1a in glioma cells reduces migration in vitro and invasion in vivo and impairs their ability to form tumor spheres. Mol Cancer 9: 133, 2010.

32. Wang Z, Shi Q, Wang Z, et al: Clinicopathologic correlation of cancer stem cell markers CD44, CD24, VEGF and HIF-1 $\alpha$ in ductal carcinoma in situ and invasive ductal carcinoma of breast: an immunohistochemistry-based pilot study. Pathol Res Pract 207: 505-513, 2011. 